\title{
Referate
}

Just, E. E., The biology of the cell surface. Philadelphia Pa., P. Blakiston's Son \& Co., 1939. XI + 392 S., 42 (teilweise farbige) Fig. Preis geb. $\$ 5,50$.

Die einleitenden Kapitel sind aus der Beschäftigung mit tierischen Eiern hervorgegangen und behandeln die Bedeutung des Experimentierens, die Natur des Proto- und speziell des Ektoplasmas. Verf. will die überragende Bedeutung gerade des Ektoplasmas für die Beziehungen der Zelle zur Außenwelt und für ihre Lebensbetätigung hervorheben. Als grundlegende Kennzeichen des Lebenszustandes betrachtet er außer Atmung und Leitfähigkeit für Reize vor allem das Kontraktionsvermögen und diese Charaktere kann er in hohem Grade für das Ektoplasma nachweisen; alle drei werden erheblich durch dessen Wassergehalt modifiziert. Eine Rejhe weiterer Kapitel befaßt sich mit Fragen der Befruchtung, Parthenogenese, Zellteilung und -differenzierung und mit der Beteiligung des Ektoplasmas an diesen Vorgängen. Schließlich behandeln die hauptsächlich die theoretischen Diskussionen enthaltenden Kapitel Beziehungen des Ektoplasmas zu den Chromosomen und zu Problemen der Entwicklung, die es beherrscht. Sicher wird der Leser nicht allen Gedankengängen ohne Widerstreben folgen können, aber unbeschadet solcher Zurückhaltung bilden die Darbietungen, die sich auf eine reichliche experimentelle Beschäftigung mit Protoplasten verschiedenster Art (hauptsächlich tierische Eier) gründen, eine Fundgrube für Anregungen aller Art. Ein besonderes Lob verdient die ganz ausgezeichnete Ausstattung des Werkes.

\section{Pfeiffer (Bremen)}

Handovsky, H. et Hauss, L., Le rH de quelques hormones. Bull. Soc. Chim. biol. 21, 112-114, 1939.

Polarographische Bestimmungen verschiedener wässeriger Extrakte des vorderen Hypophysenlappens ergeben $\mathrm{E}_{\mathrm{h}}$-Werte von $-0,23$ Volt bei gonadotropem oder - 1,65 Volt bei thyreotropem Effekt. Pfeiffer (Bremen).

Conard, A., Sur le mécanisme de la division cellulaire et sur les bases morphologiques de la cytologie. Bruxelles, Cock, 1939. 186 S., 5 Taf., 61 Textfig.

Die grundlegenden Beobachtungen und Versuche sind an Zellteilungen bei Degagnya majuscula und verwandten Arten gemacht worden. Fast den dreifachen Raum nimmt die Diskussion der Befunde unter Heranziehung eines großen Teiles der einschlägigen Literatur ein. In übersichtlicher Gliederung wird für alle die Teilerscheinungen der Kern- und der Cytoplasmateilung nach dem Mechanismus geforscht, wobei immer die neueren Ergebnisse der Literatur im Vordergrunde stehen. Beispielsweise sucht Verf. bei der anaphasischen Chromosomenbewegung Ansichten von K. Bělař, F. Wassermann und B. Wada mit Folgerungen aus der Kontraktionshypothese zu vereinen. An den verschiedensten Stellen finden sich Deutungsversuche mit Vorgängen der Entmischung bzw. Mischung, Entquellung bzw. Quellung, sei es im Kern oder im Cytoplasma; herabgesetzte bzw. geförderte Permeabilität der Kernmembran wird als Begleiterscheinung verminderter bzw. gesteigerter Synthesen im Kern angesehen; Hydratationen der Karyolymphe können mit Kondensationen (Entquellungen) des Karyotins einhergehen. Bei solchen Phänomenen hätte vielleicht noch auf die kolloidchemisch gesicherten synäretischen Wasserverschiebungen zwischen den beiderlei Konstituenten der Zelle hingewiesen 